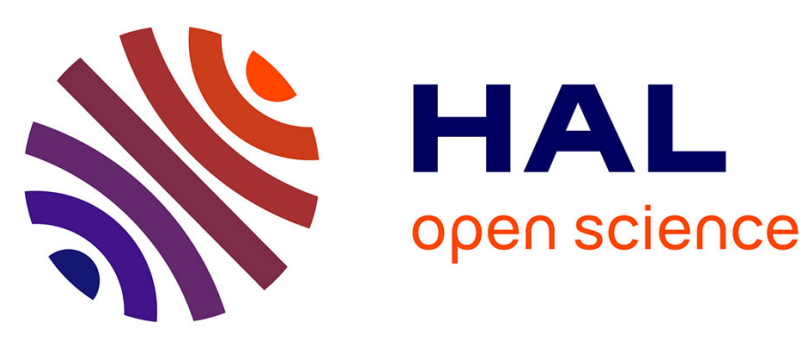

\title{
Deformation mechanisms of antigorite serpentinite at subduction zone conditions determined from experimentally and naturally deformed rocks
}

Anne-Line Auzende, Javier Escartin, Nicolas Walte, Stéphane Guillot, Greg Hirth, Daniel J. Frost

\section{To cite this version:}

Anne-Line Auzende, Javier Escartin, Nicolas Walte, Stéphane Guillot, Greg Hirth, et al.. Deformation mechanisms of antigorite serpentinite at subduction zone conditions determined from experimentally and naturally deformed rocks. Earth and Planetary Science Letters, 2015, 411, pp.229-240. 10.1016/j.epsl.2014.11.053 . hal-01110205

\section{HAL Id: hal-01110205 \\ https://hal.sorbonne-universite.fr/hal-01110205}

Submitted on 27 Jan 2015

HAL is a multi-disciplinary open access archive for the deposit and dissemination of scientific research documents, whether they are published or not. The documents may come from teaching and research institutions in France or abroad, or from public or private research centers.
L'archive ouverte pluridisciplinaire HAL, est destinée au dépôt et à la diffusion de documents scientifiques de niveau recherche, publiés ou non, émanant des établissements d'enseignement et de recherche français ou étrangers, des laboratoires publics ou privés. 
5 Anne-Line Auzende ${ }^{1, \text { now } 4}$, Javier Escartin ${ }^{2}$, Nicolas Walte ${ }^{3}$, Stéphane Guillot ${ }^{4}$, Greg Hirth ${ }^{5}$, 6 Daniel J. Frost ${ }^{3}$

7

8

9

10

${ }^{1}$ IMPMC, Universités Paris Diderot \& Paris 06, UMR CNRS 7590, MNHN, IRD UMR 2064

11 place Jussieu, F75005 Paris, France

$12 \quad{ }^{2}$ CNRS, IPGP, 1 rue Jussieu, 75238 Paris, France

$13{ }^{3}$ Bayerisches Geoinstitut, Universität Bayreuth, Universitätsstraße 30, 95447 Bayreuth, 14 Germany

$15{ }^{4}$ ISTERRE, CNRS, Université Grenoble Alpes, 38000 Grenoble, France

$16{ }^{5}$ Department of Geological Sciences, Brown University, 324 Brook Street, Box 1846

17 Providence, RI 02912, USA

18

19 Corresponding author : Anne-Line Auzende

20 phone : $+33(0) 476514066$

21 Email : anne-line.auzende@ujf-grenoble.fr

22

23 key words : antigorite, serpentine minerals, Deformation DIA, fluid migration, brittle, 24 subduction zone 


\section{Abstract}

Deformation-DIA experiments on antigorite serpentinite were performed at pressures of 1-3.5 GPa and temperatures of between 400 and $650^{\circ} \mathrm{C}$, bracketing the stability of antigorite under subduction zone conditions. For each set of pressure-temperature (P-T) conditions, we performed two runs at strain rates of $5 \times 10^{-5}$ and $1 \times 10^{-4} \mathrm{~s}^{-1}$. We complemented our study with a sample deformed in a Griggs-type apparatus at $1 \mathrm{GPa}$ and $400^{\circ} \mathrm{C}$ (Chernak \& Hirth, 2010), and with natural samples from Cuba and the Alps deformed under blueschist/eclogitic conditions. Optical and transmission electron microscopy were used for microstructural characterization and determination of deformation mechanisms. Our observations on experimentally deformed antigorite prior to breakdown show that deformation is dominated by cataclastic flow with a minor but perceptible contribution of plastic deformation (microkinking and (001) gliding mainly expressed by stacking disorder mainly). In contrast, in naturally deformed samples, deformation-related plastic structures largely dominate (stacking disorder, kinking, pressure solution), with minor but also perceptible contribution of brittle deformation. When dehydration occurs in experiments, plasticity increases and is coupled to local embrittlement attributed to antigorite dehydration. In dehydrating samples collected in the Alps, embrittlement is also observed suggesting that dehydration can contribute to intermediate-depth seimicity. Our results thus show that semibrittle deformation operates within and above the stability field of antigorite. However, naturally deformed samples record primarily plastic deformation that likely take places at low strain rates. We also document that the corrugated structure of antigorite has a control on the strain accommodation mechanisms under subduction conditions, with preferred inter and intra-grain cracking along (001) and gliding along both $a$ and $b$. We also show that antigorite rheology in subduction zones is partly controlled by the presence of fluids, which can percolate within the exhumation channel via deformation-induced interconnected porosity. 


\section{Introduction}

51

Subduction zones are the setting of numerous processes that impact the dynamics and geochemical evolution of the Earth (see Tatsumi \& Kogiso, 2003; Hirth \& Guillot, 2013). In a context where tectonic stresses dominate, the peculiar rheological properties of serpentinites focus the interest of the scientific community (see Reynard, 2013 for a review). Indeed, serpentinites are believed to be an important component of the subducting slab owing to the hydrothermal alteration of the oceanic lithosphere (Mevel, 2003; Garth and Rietbrock, 2014). Additionnally, serpentinite are present in the mantle wedge due to fluids rising from the dehydrating lithosphere, as inferred from the low seismic velocities (Hyndman \& Peacock, 2003) and the high Poisson's ratio (Kamiya \& Kobayasi, 2000) measured in the mantle wedge. These inferences from geophysical observations are supported by field evidence in paleo-subduction zones (Guillot et al, 2009) or serpentine mud volcanoes (Fryer et al, 1999). Understanding how serpentinites deform in subduction zones, particularly in the exhumation channel that overlies the subducting slab (Hilairet \& Reynard, 2009), is of prime importance to understand decoupling between the downwelling slab and the overriding plate (Wada et al, 2008), exhumation of high-pressure rocks (Guillot et al, 2001; Agard et al, 2009), controls on fluids pathways (Padrón-Navarta et a, 2010) and, more generally, the mantle wedge dynamics (see van Keken, 2003 and references therein). Also, when serpentine breaks down at depth, the embrittlement caused by the migration of dehydration fluids is believed to trigger seismicity (Dobson et al, 2002; Hacker et al, 2003; Jung \& Green, 2004; Peacock, 2001; Garth and Rietbrock, 2014). The fate of the dehydration fluids is also of great importance as they affect the properties of mantle rocks such as their rheology and melting temperature and the geochemical budget of elements that are recycled in the subduction zone (Deschamps et al, 2013; Marchesi et al, 2013). 

structural varieties: lizardite (flat), chrysotile (tubular), and antigorite (corrugated). In subduction zones, antigorite is the stable serpentine variety (Ulmer \& Trommsdorff, 1995) and its rheological behaviour has been probed by numerous experimental studies, yielding diverging results or interpretations. Some experimental studies document deformation in the (semi-) brittle regime (Escartin et al, 1997; Jung \& Green, 2004; Chernak and Hirth, 2010), while at similar deformation conditions other studies suggest that deformation operates in the plastic regime (Hilairet et al., 2007). As models of mantle wedge dynamics and fluid transport feed from these experimental data, it is necessary to better constrain and understand the precise mode of deformation of antigorite within the subduction zone, and in particular around dehydration conditions. For this purpose, we conducted experiments with a Deformation-DIA apparatus, at strain rates and total strains similar to those reported in previous studies, and coupled this experimental study with the investigation of naturally deformed samples. To facilitate the comparison of experimentally and naturally deformed rocks, we conducted experiments under P-T conditions similar to the metamorphic conditions experienced by serpentinites from the Alps and Cuba (Figure 1). The microstructures of the samples described in this study (from a few $\mu \mathrm{m}$ to $\mathrm{nm}$ ) were investigated with optical and transmission electron microscopy (TEM) to determine and interpret deformation mechanisms. Microstructural observations are indeed the key way to infer, at the micron scale, the strain accommodation processes of minerals (see Passchier and Throw, 2005), particularly for phyllosilicates (Shea and Kronenberg, 1992). Investigating both field and laboratory samples is essential in order to constrain the application field of experiments, which necessarily lack the complexity of natural systems as well as their duration. Furthermore, differences between experimental and natural microtructures should highlight the effect(s) and importance of processes not active in experiments. 


\section{Materials and methods}

101

\subsection{Experimental deformation}

Experimental device

The D-DIA high-pressure experiments were carried out at the Bayerisches Geoinstitut

105 (Bayreuth, Germany). This device is based on a DIA cubic anvil apparatus that consists of symmetric upper and lower blocks, four wedge-shaped thrust blocks and six anvils. The square truncations of the anvils define a cubic volume in which the high-pressure cell assembly containing the sample is loaded (Figure 2). The D-DIA is capable of generating pressures up to $10 \mathrm{GPa}$ at high temperatures (up to $2000^{\circ} \mathrm{C}$ ), and then deforming the sample. Hydrostatic pressure is reached at room temperature by closing up concurrently the anvils with a rate of $0.02 \mathrm{GPa} / \mathrm{min}$. Once a high pressure is attained, temperature is increased with a heating-resistance furnace made of $\mathrm{LaCrO}_{3}$, with temperature ramping up between 50 and $100^{\circ} \mathrm{C} / \mathrm{min}$. Temperature was determined using a $\mathrm{W}$-Re thermocouple inserted axially into the assembly and in contact with the top of the sample. When the required $\mathrm{P}$ and $\mathrm{T}$ are achieved,

115 the sample is annealed for a couple of hours to remove the eventual deformation-induced

116 structures acquired during cold compression. After annealing, the samples were deformed by controlled shortening of the vertical anvil axis, which induced axial compression in the cylindrical samples while keeping the confining pressure constant. Total time at high

119 temperature is ranging between about $180\left(1 \times 10^{-4} \mathrm{~s}^{-1}\right)$ and $240 \mathrm{~min}\left(5 \times 10^{-5} \mathrm{~s}^{-1}\right)$. The

120 deformation is monitored with displacement transducers. Strain and strain rate can thus be 121 controlled, and are reported for each experimental run in table 1.

123 unload the sample and prevent brittle deformation structures during decompression. The 124 retraction of the upper and lower anvils was continuously adjusted to achieve comparable 
125 displacements to those of the four lateral anvils. For further details, the configuration of the

126 D-DIA is described by Wang et al. (2003).

Experimental conditions are presented in Table 1 and Figure 1. Pressure and

128 temperature conditions reflect the HP-LT conditions experienced by natural serpentinites

129 from the Monviso and Erro Tobbio Massif in the Alps (Schwartz et al, 2000; Scambelluri et 130 al, 1995; Angiboust et al, 2011) or from Cuba (Auzende et al, 2002). They also compare well to experiments by Chernak et al (2010) conducted in a Griggs-type apparatus; Chernak et al.’s (2010) sample W1460, deformed at $1 \mathrm{GPa}$ and $400^{\circ} \mathrm{C}$ was provided by the authors in order to conduct microstructural analyses as part of this study. The deformation experiments by Hilairet et al (2007) were performed along a colder geotherm, and included several loading and unloading cyles at different strain rates. We performed systematically two experiments under each set of P-T conditions, but at different strain-rates (see Table 1). Each sample was therefore deformed in a single deformation event at a single $\mathrm{P}$ and $\mathrm{T}$ and subsequently quenched. To document possible deformation structures induced by compression or decompression, one static experiment, DD63, was pressurized at $1.8 \mathrm{GPa}$ and $550^{\circ} \mathrm{C}$,

140 annealed for two hours and then quenched and decompressed. The P-T conditions of the static 141 experiment correspond to deformation experiments DD64 and DD65 (Table 1).

\section{Starting material}

The starting material was a natural serpentinite collected in the Monviso ophiolite unit

145 (Western Alps, Italy). Originally an oceanic mantle lithosphere, the unit was buried during 146 alpine subduction and underwent HP-LT metamorphic conditions under eclogite facies conditions. The sample, taken from a preserved lens embedded within a highly sheared matrix

148 of serpentinites, is fully serpentinized, without trace of inherited minerals such as olivine or 149 pyroxene (sample 627-1, see Auzende et al., 2006). The serpentine chemistry lies within the 
normal range of antigorite composition with little aluminium $\left(\mathrm{Al}_{2} \mathrm{O}_{3}=1.97 \mathrm{wt} \%\right)$ and iron $\left(\mathrm{FeO}_{\mathrm{t}}=2.46 \mathrm{wt} \%\right)$, and the petrological investigation shows that the sample consists almost exclusively of antigorite blades up to several tens of $\mu \mathrm{m}$ in length, associated with magnetite. This sample, masssive and unfoliated at the macroscopic scale, displays under a light microscope a typical interpenetrative texture with no preferred orientation and without noticeable deformation-induced structures under a light microscope (no crystallographic preferred orientation, thereafter referred as CPO), as shown on Figure 3a. TEM characterisation of this sample shows crosscutting antigorite blades, displayed on Figure $\mathbf{3 b}$. Furthermore, at this nanoscale, no significant evidence of deformation was observed either.

For experiments, cylindrical cores $1.4 \mathrm{~mm}$ in diameter, and $1.6 \mathrm{~mm}$ in length were drilled in the bulk rock, and loaded in the D-DIA assembly designed for high-pressure experiments, as presented in Figure 2a. Materials constituting the assembly have been chosen for their physical (e.g., compression modulus) and chemical properties (no reaction with the sample) at experimental conditions.

\subsection{Naturally-deformed samples}

Sheared serpentinites are common in nature, but their deformation is often linked to retrograde, low P-T conditions. Instead, we have selected sheared serpentinite samples with inferred deformation occurring during prograde or peak metamorphic conditions (see Table 1), to facilitate comparison with experimental results.

Samples Cu12 and Cu24 sample were collected in the Escambray massif (Cuba) from an eclogitic unit (Auzende et al, 2002), that deformed at the metamorphic peak conditions affecting also the associated eclogitic metabasite, which shows a paragenesis consisting of almandine garnet + omphacite $(\mathrm{Jd} 40) \pm$ glaucophane + phengite $(\mathrm{Si} \sim 3.4 \mathrm{pfu})+$ paragonite + zoisite + quartz + rutile. Sample Al24 was collected in the Erro Tobbio unit, in the alpine 
175 Voltri massif (Italy), which records different steps of burial during subduction. Hermann et al

176 (2000) evaluated the metamorphic conditions of unit I (labelled ET1 in Fig.1), where Al24

177 was collected, at $\mathrm{P}=0.9 \pm 0.3 \mathrm{GPa}$ and $\mathrm{T}=360 \pm 60^{\circ} \mathrm{C}$. Deformation structures are

178 synchronous with prograde metamorphism. Samples Al19 and Al20 (labbeled ET3 in Fig.1)

179 were also collected in the Erro Tobbio unit and underwent more severe metamorphic

180 conditions, which Hermann et al. (2000) evaluate at $\mathrm{P}=2.0 \pm 0.2 \mathrm{GPa}$ and $600 \pm 40^{\circ} \mathrm{C}$ (ET3).

181

182

183

184

185

186

187

188

189

190

191

192

193

194

195

196

197

198

199

\subsection{TEM observations}

All samples, natural or experimental, were prepared for microstructural characterisation using an ion-polishing system, which provides for each sample large thin sections. Prior to thinning, the experimental cells were embedded in epoxy resin and cut parallel to the shortening direction with a $20 \mu$ m-wire saw. The natural samples were cut perpendicular to the foliation direction. All samples were glued with Crystal Bond thermofusible epoxy onto a glass slide, thinned, and polished down to $30 \mu \mathrm{m}$. TEM preparations were optically selected from the polished petrographic sections. A copper slot (1 $\times 2 \mathrm{~mm}$ ) was glued to surround each selected area, cored with a razor blade, and removed by heating the thermofusible epoxy. We used a conventional ion-milling system (PIPS for precision ion polishing system) with an argon beam operated at $5 \mathrm{kV}$. Electron transparency suitable for high-resolution imaging is achieved at the edge of the hole created by the milling beam. Amorphous zones were removed by decreasing the operating conditions down to 2.5 kV. TEM was performed at IMPMC (Paris, France). Imaging, diffraction and chemical data were obtained with a JEOL 2100 microscope with a LaB6 filament and a JEOL 2100F with a field emission gun, both operating at 200kV and equipped with JEOL EDX detectors. Table 2 lists and describes the deformation-related microstructures that were observed in experimentally and naturally deformed antigorite serpentinites. 


\section{Results}

\subsection{Experimental deformation}

203 To discriminate between structures inherited from the starting material and those generated 204 during compression/decompression, we examined by optical microscopy and TEM both the 205 starting material and sample DD63, which was statically pressurized to $1.8 \mathrm{GPa}$ and annealed 206 for two hours at $550^{\circ} \mathrm{C}$ before temperature quenching and decompression. The petrological 207 investigation of these two samples shows no significant differences. The original interpenetrative textures are recognized in the pressurized sample (Figure 3c), which displays intercrystalline cracks that we attribute to cold decompression. TEM observations of the

210 DD63 sample show large crosscutting antigorite blades typical of interpenetrative textures 211 and similar to those observed in the starting material (Figure 3b). A few chrysotile veins are observed in both samples, probably inherited from oceanic hydrothermal circulation or late retrogression of serpentinite 627-1 during exhumation. Based on these observations, we can assume that pressurization and depressurization do not induce changes to texture beyond the

215 decompression micro-cracks, which remain open and are easily recognizable in the deformed 216 samples.

We conducted experiments under two sets of P-T conditions within the stability field of 220 antigorite (Table 1 and Figure 1). These conditions reflect those experienced by natural 221 serpentinites involved in subduction. We report the results obtained on our D-DIA samples 222 and on sample W4160 provided by L. Chernak. In all samples, decompression cracks sub223 perpendicular the shortening direction are observed (Figure $4 \mathrm{~b}$ and c) and will not be taken

224 into account when discussing the deformation-linked microstructures. 
225 Observed under a polarized light microscope, the four deformed samples share several 226 features showing that deformation is not pervasive. The original interpenetrative texture is 227 well preserved and has a grain size similar to that of the starting material, with antigorite 228 blades that can reach several tens of micrometers (Figure 4a). None of the experimentally 229 deformed samples display penetrative foliation or schistosity. A few features associated with 230 localized deformation can however be recognized at this scale. In W1460, a sharp fault crosscuts the sample at a $45^{\circ}$ angle with respect to $\sigma_{1}$, and has an apparent displacement of about $200 \mu \mathrm{m}$. A second type of localization is observed in two samples (DD61, DD65), in the form of narrow damaged zones (about $10 \mu \mathrm{m}$ wide) that originate at the corner of the 234 alumina piston and propagate diagonally throughout the sample (Figures $2 \mathbf{d}$ and $\mathbf{4 b}$ ). These 235 sheared zones propagate at an angle about $30^{\circ}$ from $\sigma 1$ in DD65 and with slightly steeper angle of $\sim 40^{\circ}$ in DD61, and display no apparent displacement (e.g., offset at sample edge).

237 We attribute these features to an inhomogeneity of the distribution of deformation linked to 238 the impingement of the piston (stress shadows). These damage zones are not as sharp as the 239 fault observed in sample W1460 (Figure 4c), deformed at conditions similar to DD60 and 240 DD61. Locally, grains with significant CPO can be observed at the vicinity of the damaged 241 zones from our D-DIA samples (Figure 4b) and along the fault observed in W1460, as 242 previously described by Chernack et al (2010). This is not a common feature in these samples, 243 and we attribute it to the fault being locally parallel to pre-existing crystal orientation, and exploiting optimally oriented grain boundaries at a local scale.

We conducted extensive TEM characterization of all deformed samples, and acquired 246 more than 400 micrographs, which provide a comprehensive overview of nanostructures. 247 Overall quantification of the various structures (e.g., fracture or dislocation density) observed 248 in the experimentally deformed samples is not possible, due to the inhomogeneous 249 distribution of the deformation within each sample and the great difficulty to acquire a 
250

251

sufficiently large set of TEM images to perform statistical analyses. However, our systematic TEM observations do document clear microstructural patterns. According to these observations, we do not observe significant differences among samples deformed under conditions below the antigorite dehydration temperature.

Large interpenetrative blades of antigorite, similar to those in the starting material, are the most widespread texture. Decompression cracks can easily be recognized, as they are open fractures sub-perpendicular to $\sigma 1$. We also document distinctive microstructures that we can link to experimental deformation. Figures 5a and $\mathbf{b}$ show grains of antigorite displaying cataclastic deformation, as indicated by broken-up crystals with sharp edges, a heterogeneous grain size, and predominant delamination along the basal planes in addition to fractures at random orientations. This micro-fracturing results in local grain-size reduction and the development of incipient cataclasite textures arising from local grinding of crystals, surrounded by sample material that shows a lowr degree of deformation. These deformation textures can be observed in all samples, but are particularly common in DD60 and DD61, deformed at $1 \mathrm{GPa}$ and $400^{\circ} \mathrm{C}$. Further evidence of brittle behavior is the occurrence of intracrystalline fractures (Figure 5c and d) that affect large crystals, mainly along the cleavage planes, or associated with the bending/kinking of antigorite blades. All of these structures strongly emphasize a brittle behavior of antigorite under the P-T conditions of subduction, but at experimental strain rates that are high relative to natural strain rates.

Coupled to these brittle structures, we also observe features associated with plastic deformation, such as kinking, as shown in Figures 5d and e (DD60 and DD65) and in Figure 5f (W1460). As observed on the micrographs, gliding occurs in the basal planes along $a$ or $b$ directions (Figure 5d-e and Figure 5f respectivelly). As shown in the insert of Figure 5e, gliding along $a$ is commonly accompanied by significant stacking disorder. Kinking can be associated with cracks that develop at the hinges of the kinks ( $F$ in Figure 5d) or with 
275 dislocation walls that propagate within the bands (DW in Figure 5f). Kink-bands are 276 observed in all deformed samples, but they are not very abundant and cannot accommodate a 277 significant amount of the permanent strain. We also noted that in all deformed samples, most 278 antigorite crystals are well ordered (Figure 5g), as observed in the starting material, with a 279 constant modulation wavelength, and a regular layer stacking. Intracrystalline disorder 280 (stacking faults, twinning, offset) can be recognized only in some crystals, commonly in those 281 affected by deformation structures such as kinking (Figure 5e - insert), or in crystals in the vicinity, demonstrating that intra-crystalline defects are deformation-related (Figure 5g). A final type of structure recognized in these samples is the local development of packets of antigorite lamellae less than $500 \mathrm{~nm}$ in thickness, and elongated along the direction of cleavage (Figure 5c for instance), similar to those observed in deformed micas (e.g., Frey and Robinson, 1999).

Experiments with evidence for dehydration

Two sets of deformation experiments were conducted under conditions above the thermal stability of antigorite (Figure 1 and Table 1). Observations on the thin sections prepared from 291 the recovered samples (DD58, DD59 and DD66) show various amounts of unreacted antigorites coexisting with small grains $(<<1 \mu \mathrm{m}$ in size) of neoformed olivine (Figure $4 \mathbf{d}$ and $\mathbf{e}$ ), which is a reaction product of the antigorite dehydration (see Figure 1). We consider the identification of neoformed olivine as necessary and sufficient evidence of dehydration. We did not observed enstatite or chlorite (to accommodate $\mathrm{Al}_{2} \mathrm{O}_{3}$ excess in antigorite) nor 296 "talc-like" crystals (Perrillat et al, 2005) that could be expected under these conditions; however, considering the small grain size of these new phases (a few tens of nanometers), we cannot exclude their presence. The occurrence of secondary olivine is particularly clear in 
indicated by the work of Ulmer and Trommsdorff (1995) for the corresponding experimental pressure. We thus confirm the updated curve proposed by Ulmer \& Trommsdorff (1999) and also results from Hilairet et al (2006) (Figure 1). Optical observations in DD58 and DD59 show that olivine represents less than $5 \%$ in volume of the samples, meaning that the amount of released water should be very low ( $<0.7$ vol\% overall), while sample DD66 displays $~ 50 \%$ of neoformed olivine. The distribution of olivine is clearly restricted to narrow domains

306 (indicated by blue arrows in Figure 4e), suggesting that water from the dehydration reaction 307 was released within the areas where olivine is observed, locally increasing the water/rock ratio and pore fluid pressure.

The analysis of the recovered samples also showed that a foliation did not develop either under these extreme conditions, and that the remaining antigorite preserves the original interpenetrative texture (Figure 4d). However, localized domains with significant CPOs of antigorite together with olivine grains develop perpendicularly as well as obliquely (about $45^{\circ}$ ) to the compression direction, suggesting a more important contribution of plastic processes under these higher P-T conditions.

At the TEM scale, the decreased abundance of cataclastic textures in the dehydrated samples

316 is the main difference with respect to those deformed within the stability field of antigorite, where these structures are common. Brittle structures are still present, however, and occur as 318 microcracks that are locally decorated by neoformed grains of olivine along the open crack (Figure 6a). Such repartition of the byproducts of antigorite dehydration at the edge of the crack unambiguously links this microfracturating to dehydration. The olivine grains are 321 almost xenomorphic in shape, ranging in grain size from a few tens of nanometers to a few tens of micrometers. In these samples we also observed that plastic structures are significantly more frequent in antigorite. We observed more abundant kinking (Figure 6b) and an increase of both the number of disordered antigorite crystals and of the amount of intracrystalline 
disorder itself within these grains (Figure 6c). Antigorite lamellae are also found in the samples. Figure 6d shows a highly strained antigorite crystal, with dislocations putatively migrating and concentrating to create dislocation walls that can evolve into new grain boundaries (subgrain formation). This process may explain the formation of antigorite packets observed in all deformed samples. Locally, we also observed lattice orientations, but no preferential orientation shared within the whole sample. Finally, in the selected region prepared for TEM investigations in sample DD66, olivine is the main phase observed, and therefore it cannot be used to constrain the deformation behavior of antigorite.

\subsection{Naturally deformed samples}

Petrological examination of the samples collected from the eclogitic unit of the Escambray massif in Cuba (Cu12 and $\mathrm{Cu} 24$ ) show that they consist mainly of antigorite blades, unambiguously identified by Raman spectroscopy and TEM (Auzende et al, 2004). They display a visible foliation, attributed to eclogitic deformation (Figure 7a). However, the antigorite blades are mostly undeformed, as shown both by the shape of the blades and the clear and uniform extinction under cross-polarized light, indicating that antigorites have massively recrystallised under eclogitic conditions. In these samples, there is no evidence of antigorite breakdown, as no olivine is observed. Serpentinite Al24 is an antigorite mylonite deformed during the first steps of the burial of the Erro Tobbio series (Unit I), under conditions close to those of experiments DD60-DD61 (Hermann et al, 2000; Auzende et al, 2006). Deformation manifests itself by the development of olivine-free shear bands (Figure 7b). These three samples were naturally deformed under conditions that can be related to our non-dehydrated experiments.

Serpentinites Al19 and Al20, also collected in the Erro Tobbio unit (Unit III), were also deformed during the burial of this unit, but under more severe metamorphic conditions than 
those of serpentinite Al24. Indeed, they reach dehydration conditions (antigorite + brucite $\rightarrow$

351 olivine + water) resulting in the opening of veins filled with antigorite destabilisation products. Antigorite crystals are elongated along the foliation (Figure 7c). They are intensely sheared, and display undulatory extinction, characteristic of deformed crystals. This is confirmed by micrometric kink-bands visible under the light microscope. Veins filled with metamorphic olivine \pm titanoclinohumite, resulting from the dehydration of antigorite, can be observed on metric outcrops (Hermann et al, 2000) as well as in thin sections (Figure 7c). These veins crosscut the foliation defined by the antigorite blades, and developed under eclogitic conditions that fall between those experimentally imposed for DD64-DD65 (no evidence of dehydration) and DD58-DD59 (appearance of metamorphic olivine).

360 At the TEM scale, we observe that natural samples display a greater amount of plastic structures (e.g., crystal disorder) compared to the experimentally deformed samples. In particular, approximately two-thirds of the crystals are highly disordered, and intracrystalline faults (stacking disorder, twinning, offset or dislocations) are very common, as illustrated on

Figure 8a and b. This is particularly noticeable in the case of Erro Tobbio samples, where inherited antigorites have been highly sheared. In the Escambray massif samples, the density of defects in crystals is smaller. Antigorite commonly occurs as large oriented blades elongated along the foliation direction (Figure 8e), and display a modulation of dislocations that are scattered within the crystals, as shown on Figure $\mathbf{8} \mathbf{b}$ and $\mathbf{g}$. Minor chrysotile veins can be observed in most of the samples (Fig. 8f). In the Erro Tobbio samples it is also common to observe zones of recrystallisation at the interface between grains (Figure 8c and d), which were not observed in experimentally deformed samples. In a few cases we can document that the current grain boundary is a crack splitting an initial single crystal (Figure 8d, possibly 8c), as previously shown by Auzende et al (2006). These brittle structures, while 
not widespread in the naturally deformed samples, are significant. We did not observe any

375 cataclastic textures in any of the investigated natural samples.

376 The main feature that can be identified within all investigated natural samples is the amount 377 of intra-crystalline disorder. We observed a greater amount of crystal defects in highly 378 sheared antigorites from all Erro-Tobbio samples compared to the less-sheared antigorite 379 sampled in Cuba. We cannot observe any clear difference between samples deformed prior to 380 or after water release from antigorite destabilization along the subduction path.

\section{Discussion}

\subsection{Lattice control of the deformation-induced microstructures in antigorite}

Microstructures from experimentally and naturally deformed serpentinites can be used to constrain how serpentinites accommodate deformation under high-pressure conditions (i.e., subduction zone conditions). These microstructures are controlled by the crystallographic promotes a different style of accommodation than typical to other phyllosilicates, such as

390 lizardite (a flat serpentine variety) or micas. The brittle microstructures recognized in the investigated samples range from limited microcracking, affecting antigorite crystals (Figure

394 characterized by a layered structure and weak hydrogen bonding along the basal planes 395 (Mellini, 1982). Thus, as expected, we noted that most of the cracks propagate along the (001) 396 cleavage direction (Figure 5) and create new grains elongated along the two other crystallographic directions, as documented in deformed lizardite (Escartin et al, 1997: Viti \& 
deformed antigorite crystals, coupled to solid rotation of the grains to create a shape preferred orientation as a response to stress and deformation, should contribute to the strong CPO, namely the $c$-axis clustering observed in naturally foliated antigorite serpentinites (van de Moortele et al., 2010; Padrón-Navarta et al., 2012). Beside (001) delamination, intragranular microfractures that crosscut antigorite crystals (Figure 5c) can be explained by the relatively high strength of antigorite relative to other sheet silicates due to the layer reversals, with $\mathrm{Si}-$ O-Si bonds along $c^{*}$ linking the layers (Kunze, 1956; Christensen, 2004). A significant proportion of these intracrystalline microfractures can be considered as features formed when the limit of plasticity of the material is reached, during kinking or bending (Figure 5d). This corresponds to a distinct type of intracrystalline fracturating, which can be interpreted as a response to a local accumulation of stress due to the lattice accommodation of the kinking. Indeed, kinking is characterized by migrating dislocations that increase the internal strain energy in the antigorite crystal (see Passchier and Trouw, 2005).

A distinct type of microcracks can unambiguously be attributed to dehydration of antigorite, as clearly established from figure 6a. These microcracks could be ascribe to hydraulic fracturating as proposed by Dobson et al (2002) as well as to antigorite embrittlement at the onset of the antigorite to olivine dehydration reaction (Jung et al, 2004). Both process, while different, produce faulting and might be responsible for seismicity in subduction zones (Raleigh \& Paterson, 1965; Peacok, 2001; Hacker et al, 2003; Omori et al, 2004; Perillat et al, 2005). While we can hardly discuss further this issue, our results are similar, at smaller scale, to the observation reported by Jung et al (2004), who observed dehydration products of antigorite decorating surface of faults generated at high pressure. They suggested on this basis a weakening of the structure leading to faults initiating from the point where the reaction started and propagated. Fluids were evacuated while solid residue remained in place. Similar conclusions were proposed by Schubnel et al (2013) from the 
germanate olivine to spinel transition, with fractures initiating at the onset of the reaction. On the other hand, dehydrated Erro Tobbio serpentinites show large olivine veins crosscutting antigorite foliation, supporting fluid-induced vein opening. While microfractures can also be observed in natural samples (Figure 8), they are largely healed and display evidence for recrystallization, making it difficult to systematically recognize them, and nearly impossible to attribute them to any specific deformation process. A recent paper by Chernak \& Hirth (2011) proposes that weakening during dehydration is progressive and does not imply stickslip instabilities required to explain seismicity. While our results show that dehydration and brittle behavior are clearly linked, we provide that the observation of the dehydration-induced microcracking alone does not necessitate that brittle deformation was unstable.

Plastic microstructures are also strongly controlled by the crystal structure of antigorite. Mainly, the (001) basal plane of antigorite, although reinforced by the strong Si-O-Si bonding between the layers at reversals, remains a weak plane that is likely to be the main slip surface. Thus, as expected for a phase with a preferential slip plane, antigorite develops kink bands (Figure $5 \mathrm{~d}$ to $\mathrm{f}$ ). Kinking is well documented in the semibrittle deformation of talc close to dehydration conditions (Escartin et al, 2008) and is a common feature of phyllosilicate deformation (Paterson and Weiss, 1966; Shea and Kronenberg, 1992; Anderson, 2012). Recognized kink bands clearly show that basal slip can occur along both the $a$ and $b$ directions (Figure e and f respectivelly), meaning that two slip systems, (001)[010] and (001)[100], may be activated during the deformation event. Previous studies have proposed the dominant activation of either a single slip system of the latter (Hirauchi et al, 2010; Bezacier et al, 2010; van de Moortele et al, 2010) or of both (Padrón-Navarta et al, 2012), based on observations of CPO in naturally sheared serpentinites. Our study confirms that both slip systems are activated. Evidence for plastic gliding of the basal plane is also provided by the development of stacking disorder. Indeed, intracrystalline disorder in antigorite crystals 
such as the occurrence of microtwinning, offsets, or other stacking faults, are mostly associated with glide of the (001) plane along a (Table 2). Finally, in naturally deformed samples, we observed recrystallization of antigorite, as previously reported by Auzende et al (2006). Recrystallization is attributed to a pressure solution process and has recently been confirmed by Padrón-Navarta et al. (2008; 2012) and Amiguet et al (2014) in naturally sheared serpentinites. Such a mechanism can accommodate deformation very efficiently, and

455 is not directly controlled by the structure of antigorite, but by the porosity. However, as we discussed in the previous section, microcracking and the resulting porosity of antigorite serpentinite is largely controlled by its crystal structure, which indicates that pressure solution will also promote CPO in deformed serpentinites. This is in agreement with the conclusions of Katayama et al. (2009) who assume that the recorded seismic anisotropy parallel to the subduction trench is due to serpentine that deforms and generates geophysically observable $\mathrm{CPO}$, although the authors infer dislocation creep as main deformation mechanism.

\subsection{Semibrittle deformation and the influence of dehydration on plasticity}

The reported observations of experimentally and naturally deformed serpentinites clearly show the coexistence of both brittle and plastic deformation microstructures, pointing to a semi-brittle deformation regime for serpentinites under subduction zone conditions. At high pressure conditions, and within the stability field of antigorite, the significant proportion of highly fractured antigorite grains in the experimental samples suggests that most of the strain 469 is accommodated by cataclastic deformation, and that plastic deformation only accommodates 470 a small fraction of strain through basal gliding. Our results are in agreement with Chernak et 471 al. (2010) who documented semibrittle deformation of antigorite at conditions relevant to 472 subduction, as they reported faults and kink bands throughout their samples up to high 473 temperature. Jung et al (2009) also detected acoustic emission characteristic of brittle 
deformation within the stability field of antigorite; their samples were initially faulted and 475 acoustic emissions were attributed to repeat frictional sliding along these preexisting faults. 476 Here, we have confirmed these observations through the characterization of sample W1460, deformed at $1 \mathrm{GPa}$ and $400^{\circ} \mathrm{C}$, in which we recognized kink bands together with brittle 478 features in the form of sample-scale faults accommodating a displacement of 200 479 micrometers, a type of localized deformation lacking in our D-DIA samples. We posit that our 480 experiments document the same type of antigorite deformation described by Chernak et al. 481 (2010), even though our samples did not display significant localization, probably due to differences in experimental set up, inhomogeneous deformation distribution, or both. We can also compare our results with those of Hilairet et al. (2007) from deformation of an antigorite sample under subduction zone conditions in a D-DIA apparatus. These experiments were 485 conducted at similar strain rates but to a slightly lower total strain, and at $4 \mathrm{GPa}$ and $400^{\circ} \mathrm{C}$, as 486 they considered a colder geotherm (see Figure 1). Hilairet et al. (2007) discussed deformation mechanisms based on stress-strain curves obtained in situ with x-ray synchrotron analyses, and fitted their data with a dislocation creep power law. They assumed that antigorite accommodated deformation plastically, based on the absence of stress drops and on the apparent homogeneous deformation of the sample. While their data are consistent with an effective flow law, our microstructural observations suggests that this behaviour is likely not purely plastic, but attributable to distributed semibrittle deformation, with an important component of brittle deformation. Under these conditions strain localization is not efficient 494 and deformation may proceed without significant stress drops. Also, as antigorite only has 495 two easy slip systems - (001)[010] and (001)[100], it does not satisfy the von Mises criterion 496 that requires five independent slip systems for plastic flow to occur homogeneously (von 497 Mises, 1928). Thus, deformation by dislocation creep can hardly accommodate the total strain 498 imposed on the samples, and requires other deformation mechanisms, as indicated by Padrón- 
Navarta et al. (2012). Our conclusions are also consistent with the results by Escartin et al.

500 (1997) who deformed antigorite under low-grade conditions (from $50 \mathrm{MPa}$ to $1 \mathrm{GPa}$ and room temperature) relevant to deformation of the oceanic lithosphere. The results from our study further support that deformation of antigorite from the subduction initiation down to antigorite breakdown depths (about $150 \mathrm{~km}$ ) occurs in the semibrittle regime.

504 At conditions above the thermal stability of antigorite, we simultaneously observed an 505 increase of plastic structures (greater intracrystalline disorder, recrystallization) together with 506 a change in the nature of the brittle features. Indeed, cataclastic structures are lacking in 507 dehydrating serpentinites and in several instances microcracks can unambiguously be linked 508 to dehydration (Figure 6a). Although only a very small amount of $\mathrm{H}_{2} \mathrm{O}$ was released in the 509 DD58 and DD59 samples due to dehydration, water locally promoted both plastic and brittle 510 behaviour. We assume that while dehydration process promotes brittle behavior, as discussed 511 in the previous section, aqueous fluid saturation together with higher temperature may have 512 enhanced plasticity, as, for instance, previously observed in olivine (Mei and Kohlstedt, 2000; 513 Jung and Karato, 2001). This plasticity manifests through higher crystal disorder of inherited 514 crystals and recrystallisation due to pressure solution. While pressure solution is a direct 515 result of water saturation, intracrystalline disorder should also be strongly enhanced by higher temperatures. We converge with Padrón-Navarta et al (2008) as they have also documented 517 an increase of intracrystaline disorder in dehydrating antigorite from Cerro del Amirez and 518 efficient pressure solution. The coexistence of brittle and plastic structures is also documented 519 in dehydrating lizardite, as documented by Viti and Hirose (2009). This apparently diverges 520 from the interpretation of Chernak and al. (2010) as they do not report brittle features in their 521 samples deformed above antigorite breakdown. However, as we did not observed significant 522 localization in our experimentally deformed samples displaying brittle microstructures, we 
assume that a TEM investigation on Chernak's dehydrated samples may potentially reveal microcracks similar to those that we have observed.

\subsection{Permeability and fluid migration in subduction zone}

A recent experimental study by Kawano et al (2011) has shown that antigorite serpentinite, under low confining pressure (50 $\mathrm{MPa}$ ) at low temperature, and without deformation, has a very low permeability, among the lowest of metamorphic rocks, but noted a significant anisotropy of the permeability: $10^{-22} \mathrm{~m}^{2}$ when measured perpendicular to the foliation, and two orders of magnitude higher $\left(10^{-20} \mathrm{~m}^{2}\right)$ when measured parallel to it. We have shown that deformation at high pressure, under conditions relevant to subduction zones, produces microcracks and therefore porosity mostly along the basal planes of antigorite, likely as mixed-mode I-II microcracks (Escartin et al., 1997), and we thus expect that permeability would be greatly increased in the plane defined by cleavage, and that fluid circulation may be controlled by this anisotropic permeability structure. Indeed, this porosity can be interconnected, as microcracks should align in the same directions due to rigid rotation of the grains as response to the stress. This is supported by several studies that have shown that basal planes of antigorite are aligned with the foliation of natural serpentinites (van de Moortele et al, 2010; Padrón-Navarta et al, 2012). In subduction zones, Katayama et al (2009) propose that the observed trench-parallel anisotropy is due to serpentine deformation that results in antigorite basal cleavage (and foliation) is parallel to the suduction plane. Thus, oriented microcraking will enhance the percolation of aqueous fluids along the foliation direction (Figure 9), as suggested in prior studies (e.g., Escartin et al., 1997; Kawano et al., 2011). Also, intragranular microcracks observed in experimentally and naturally deformed samples (Figure 5c and 8d respectively) can allow fluid migration in directions across the foliation, and thus across the deformation zone (Figure 9). 
548 In subduction zones, highly deformed serpentinites are commonly recognized in the 549 serpentine channel above the subducting slab (e.g. Guillot et al, 2009). Katayama et al (2009) 550 support this statement and emphasize the preferred orientation of antigorite crystals above the 551 subducting slab, along the trench. Our results support the hypothesis that fluids likely migrate 552 within the serpentinites, consistent with evidence for aqueous fluid percolation through these 553 rocks, which include chrysotile veins as in Figure 8d (e.g., Andreani et al, 2007), and 554 evidence for pressure solution as in Figure 8c (e.g., Auzende et al, 2006; Padrón-Navarta et al, 2012). Geochemical observations also point toward aqueous fluids in the subducting serpentinites. Indeed, Deschamps et al (2013) proposed that the observed enrichment of light rare earth elements in subducted serpentinites could be ascribed to sedimentary-derived fluid interacting with rock within the subduction channel after the serpentinization. Thus, all these observations suggest that in spite of low permeability measured experimentally at the sample scale and under static conditions (Kawano et al, 2011), aqueous fluids in the subduction system seem to rather efficiently percolate in the serpentinite. This percolation likely allows the development of the thin hydrated serpentine layer above the subducting slab due to the buoyant ascent of the fluids via an oriented connected porosity network (i.e., along the foliation), and also leading to the hydration of the mantle wedge through water transport across the foliation of the deformation zone (Figure 9). This across-foliation water transport is likely to be significantly less efficient than the along-foliation, owing to the nature of brittle deformation processes described above, and operate throughout the subduction zone.

4.4. Input of the comparison between Nature and experiments on deformation of antigorite during subduction

All our observations of natural and experimental samples indicate that antigorite serpentinites deforms in the semibrittle regime up to its complete dehydration. Optically, the 
main difference between naturally and experimentally deformed antigorite serpentinites is the

574 presence of a penetrative foliation in the former that was induced by deformation, which is not observed in experimental samples. Yet, at the TEM scale, both types of samples reveal both brittle and plastic structures. In experiments conducted within the stability field of antigorite, it has been shown that cataclastic flow controls the rheological behaviour of serpentinite, while microstructures in natural samples instead suggest a significant contribution of plasticity, with a foliation indicative of more homogeneous deformation. The absence of foliation and lesser contribution of plasticity in experimental samples can surely be attributed to i) the higher strain rates during experimental deformation $\left(5 \times 10^{-5}\right.$ and $1 \times 10^{-4}$ during D-DIA experiments compared to $10^{-12}-10^{-14} \mathrm{~s}^{-1}$ in nature), ii) to the limited strains achieved in experiments that do not allow a steady state flow (a few percent shortening in the laboratory and extremely high values in the field), as stated by Chernak et al (2010), and iii) to the absence of fluids promoting syntectonic growth that likely takes place in natural shear zones within the subduction zone. Also, most experimental samples are deformed in axial compression while natural samples are typically deformed under simple shear. This means that experimental results cannot be used to constrain the conditions under which this foliation develops in nature, as such processes cannot be replicated in laboratory experiments at the moment. Nonetheless, while low strain rates may be responsible for foliation developement, we assume that brittle features recognized in natural samples can be attributed to higher strain rates events that may or may not have a seismic origin, as stated by Chernak \& Hirth (2011).

The presence of aqueous fluids derived from the dehydration of other hydrous phases during burial (see Poli and Schmidt, 1998) in natural samples subducted and exhumed under conditions below antigorite breakdown can be suggested by the presence of chrysotile veins (Figure 8b) or indication of pressure solution evidence (Figure 8c), as both structures require the presence of fluids. The significant amount of plastic microstructures in natural samples 
598 can also be promoted by the presence of aqueous fluids together with higher temperature, 599 even under conditions below antigorite breakdown. This is supported by the greater amount 600 of plastic structures in experimentally dehydrated samples. We thus conclude that brittle 601 deformation in subduction zones is likely associated with high strain-rate events such as 602 deformation associated with seismicity, ocurring from throughout the subduction zone from 603 the surface to the depth of antigorite breakdown. Plastic deformation developing foliation 604 likely occurs at lower strain rates and under water saturation. Semi brittle deformation of antigorite can thus potentially generate a permeability network throughout the subduction system, with efficient transport along the deformation zone, and more limited one across it.

608 5. Conclusions

609 This work presents detailed microstructural observations to determine the mode of 610 deformation in both experimentally and naturally deformed samples at subduction conditions, 611 and near antigorite breakdown. Our results show that:

612 - Antigorite deforms in the semibrittle regime at high pressure. Brittle deformation in 613 subduction zones is likely associated with high strain-rate events, including seismic events 614 and can overimprint low strain-rate plastic deformation microstructures.

615 - The relative importance of brittle deformation relative to plastic deformation is likely 616 promoted by a combination of the presence of water (elevated pore fluid pressures and 617 dehydration), higher temperature and elevated strain rates.

618 - The crystal lattice structure of antigorite favours microcracking along (001), which promotes 619 interconnected porosity along the foliation direction in subduction zones. Antigorite structure 620 also induces significant intragranular fracturing. Semibrittle deformation can thus sustain a 621 permeable deformation zone down to the level of antigorite dehydration. 
622 - Owing to a likely anisotropic permeability network, aqueous fluids may migrate more

623 efficiently along the surface of the subducting slab than across it, exploiting the microporosity

624 developed along the foliation during brittle deformation events. Across-deformation zone

625 migration may be facilitated through intragranular fracturing, resulting in an upward

626 migration towards the mantle wedge above the subduction plane allowing its hydration.

627

628 Acknowledgements: The authors wanted to thank J.A. Padrón-Navarta and a second

629 reviewer for their great work reviewing this manuscrit. We are also grateful to the BGI

630 Bayreuth technical staff for assistance with the preparation of the recovered samples. This

631 work was supported by PNP and SYSTER Program (INSU/CNRS) and BGI "IHP Access to

632 Research Infrastructure program. G. Hirth was supported by National Science Foundation

633 grant EAR-0810188 for experiment W1460 used in this study.

634

635

636 
637 Table 1 : Experimental conditions for D-DIA and Griggs runs, and metamorphic conditions

638 undergone by natural samples

\begin{tabular}{|c|c|c|c|c|c|c|}
\hline \multicolumn{7}{|c|}{ Experimentally-deformed serpentinites } \\
\hline Sample & $P(G p a)^{\star}$ & $\mathrm{T}\left({ }^{\circ} \mathrm{C}\right)^{\star}$ & $\begin{array}{l}\text { Strain } \\
\text { rate }\end{array}$ & $\begin{array}{l}\text { Total } \\
\text { strain }\end{array}$ & $\begin{array}{l}\text { dehydration } \\
\text { evidence }\end{array}$ & Ref \\
\hline DD60 & 1.0 & 400 & $5 \times 10-5$ & $24 \%$ & none & This study \\
\hline DD61 & 1.0 & 400 & $1 \times 10-4$ & $26 \%$ & none & This study \\
\hline DD63 & 1.8 & 550 & - & static & none & This study \\
\hline DD64 & 1.8 & 550 & $1 \times 10-4$ & $28 \%$ & none & This study \\
\hline DD65 & 1.8 & 550 & $5 \times 10-5$ & $27 \%$ & none & This study \\
\hline DD58 & 2.5 & 650 & $1 \times 10-5$ & $8 \%$ & olivine & This study \\
\hline DD59 & 2.5 & 650 & $1 \times 10-4$ & $26 \%$ & olivine & This study \\
\hline DD66 & 3.5 & 650 & $5 \times 10-5$ & $30 \%$ & olivine & This study \\
\hline W1460 & 1.0 & 400 & $1.5 \times 10-5$ & $33 \%$ & none & Chernak et al, 2010 \\
\hline \multicolumn{7}{|c|}{ Naturally sheared serpentinites } \\
\hline Sample & $P(G P a)$ & $\mathrm{T}\left({ }^{\circ} \mathrm{C}\right)$ & \multicolumn{2}{|c|}{ Origin } & $\begin{array}{l}\text { dehydration } \\
\text { evidence }\end{array}$ & Ref \\
\hline Cu12 / Cu24 & $1.2 \pm 2$ & $450 \pm 30$ & \multicolumn{2}{|c|}{ Escambray, Cuba } & none & $\begin{array}{l}\text { Auzende et al, } \\
2004\end{array}$ \\
\hline Al24 (ET1) & $0.9 \pm 3$ & $\begin{array}{c}360 \pm \\
60\end{array}$ & \multicolumn{2}{|c|}{ Erro Tobbio, Alps } & none & Hermann et al, 2000 \\
\hline $\begin{array}{l}\text { Al19 / Al20 } \\
\text { (ET3) }\end{array}$ & $2.0 \pm 2$ & $600 \pm 40$ & \multicolumn{2}{|c|}{ Erro Tobbio, Alps } & $\mathrm{ol}+\mathrm{TiCl}$ & Hermann et al, 2000 \\
\hline
\end{tabular}

639 * errors are estimated according to Wang et al (2003) $-\mathrm{T} \pm 20^{\circ} \mathrm{C}, \mathrm{P} \pm 10 \%$

640 
646 Table 2 : Description of the deformation-linked microstructures observed in antigorite

647 serpentinites (from Otten, 1993; Gorbety, 2003; Passchier \& Trouw, 2005)

648

\begin{tabular}{|c|c|c|}
\hline Type of microstructure & Abbreviation & Description \\
\hline Decompression cracks & Decomp. & Cracks due to the decompression of the assembly after temperature quench \\
\hline Shear band & SB & Wavy ductile structure which localize intense strain. Common in phyllites \\
\hline Kink band & $\mathrm{KB}$ & Tabular fold zones due to slipping of basal planes and resulting from shear couple \\
\hline Microcracks & $\mu \mathrm{C}$ & $\begin{array}{l}\text { Brittle planar discontinuity, commonly with some dilatation. High density of } \\
\text { microcracking can lead to through-going fault }\end{array}$ \\
\hline Dislocation wall & DW & $\begin{array}{l}\text { Intracrystalline planar zone that concentrate migrating dislocations. Can evolve to a } \\
\text { neoformed grain boundary (GB) }\end{array}$ \\
\hline Offset & $\mathrm{O}$ & $\begin{array}{l}\text { Lateral gliding of the layers (along } a \text { ) due to the shift of the tetrahedral reversal from TO } \\
\text { layer to the other by one tetrahedron position }\end{array}$ \\
\hline Twinning & Tw & $\begin{array}{l}\text { Mirror operation along the basal plane coupled to a gliding of the layer of } a / 2 \text {. The } \\
\text { modulations are thus shifted of half a wavelenght }\end{array}$ \\
\hline Two-layer polytype & 2L-P & $\begin{array}{l}\text { Combination of twining or offset can lead to a } 1.4 \mathrm{~nm} \text { periodicity in the } \mathrm{c}^{*} \text { direction } \\
\text { instead of } 0.7 \mathrm{~nm} \text { typical of antigorite }\end{array}$ \\
\hline Stacking defect & SD & All other possible types of stacking defects (or unrecognized) \\
\hline Modulation dislocation & MD & Termination of antigorite waves on modulation dislocations. \\
\hline Recrystallisation & $\mathrm{R}$ & Zones of recrystallisation attributed to pressure solution processes \\
\hline
\end{tabular}

649

650 
652 Figure 1 : P-T diagram plotting the experimental conditions reported in this study and from

653 previous experimental works. Curve limiting the thermal stability of antigorite are reported

654 from Ulmer \& Trommsdorff (1999) and Hilairet et al (2006). We also reported the curve

655 from Ulmer \& Trommsdorff (1995) which is widely used in the litterature but is incorrect (see

656 Ulmer \& Trommsdorff, 1999). We also plotted the metamorphic conditions undergone by

657 natural samples (ET1, 2 and 3 correspond to Erro-Tobbio metamorphic stages from Hermann

658 et al, 2000; VM, PG and LG stand for Vizzo Mozzo, Passo Gallarino and Lago Superiore

659 units described by Schwartz et al, 2000) as well as experimental conditions from previous

660 studies. Insert illustrates to the corrugated crystal structure of antigorite (dark silicate

661 tetrahedra and light magnesian octahedra)

662

663 Figure 2. a) schematic representation of the assembly prepared for the D-DIA experiment,

664 and b) photography of the assembly, c) the assembly monted in the D-DIA, d) optical

665 microscopy image of a recovered sample (DD59)

666

667 Figure 3. a) Starting material image under cross polarized light showing interpenetrative

668 texture of antigorite (Atg) serpentininite, b) TEM micrograph of crosscutting antigorite blades

669 from the starting material. c) natural light / cross polarized light mounted image of sample

670 DD63 (static run) showing decompression-induced fractures (Decomp). $\sigma 1$ is horizontal.

671

672 Figure 4. Optical microphotographs of recovered samples from non-dehydrated and

673 dehydrating experiments. $\sigma 1$ is vertical on all images except b where it is rotated of $90^{\circ}$. a)

674 typical interpenetrative texture inherited from the starting material (DD65), b) oblique

675 localized damaged zone crosscutting the sample (DD61), c) fault crosscutting W1460

676 (Chernak et al, 2010), d) Secondary micrograins of olivine associated to antigorite underline

677 the significant dehydration of DD66, e) dehydrated samples showing local concentration of

678 inframicronic grains of olivine (showed by blue arrows) (DD59).

679

680 Figure 5. TEM bright field microcrographs of recovered samples from non-dehydrated

681 experiments. a) and b) show catactlastic textures with antigorite grains cracking preferentially

682 along (001) cleavage (Cl), c) intracrystalline microcracks propagating through an antigorite

683 crystal. Antigorite lamellae can be recognized, d, e and f) antigorite crystal showing kink 
684

685

686

687

688

689

690

691

692

693

694

695

696

697

698

699

700

701

702

703

704

705

706

707

708

709

710

711

712

713

714

715

716

717

bands (KB), with a gliding of the basal planes along $a$ direction ( $\mathrm{d}$ and e) and $\mathrm{b}(\mathrm{f})$. Antigorite shown on $\mathrm{f}$ ) is observed along $<100$ ) and can be discriminated from lizardite on SAED pattern by slight tilting the crystal and revealing surstructure diffration spots (DW = dislocation wall), g) bright field and associated SAED pattern of an ordered antigorite, h) bright field and associated SAED pattern of a slightly disordered antigorite showing twinning (Tw) and stacking defects (SD).

Figure 6. TEM bright field microcrographs of recovered samples from dehydrating experiments a) and associated SAED pattern showing olivine grains (Ol) decorating the edges of a microcrack, b) and associated SAED pattern showing kinked antigorite, c) and associated SAED pattern showing highly disordered antigorite. Staking disorder is emphasized on the SAED pattern by the presence of diffuse streaks along $c^{*}$, d) antigorite crystal showing migrating dislocation walls (DW) that may evolve to grain boundary (GB)

Figure 7. Optical microphotographs of naturally sheared serpentinite samples. a) antigorite serpentinite Cu12 from the Escambray massif (Cuba). Foliation is underlined by slighthly deformed antigorite blades, highly sheared antigorite mylonite from b) unit I of Erro Tobbio (Alps) showing shear bands (SB), and c) from unit III of Erro Tobbio (Alps) showing plurimicronic kink bands and veins filled with by products of antigorite dehydration olivine et Titano-clinohumite

Figure 8. TEM bright field microcrographs of naturally sheared serpentinites showing a) high intracrystalline disorder, as observed on the micrograph and associated SAED pattern, b) high resolution image of a slightly disorder antigorite crystal with a modulation dislocation (D), c) microcrack healed by recrystallisation (R) due to pressure solution, d) microcrack with little recrystallisation, e) elongated antigorite blades, f) chrysotile veins inherited from the oceanic event or produced during fluid migration in subduction context, g) antigorite seen along $<001>$ showing modulation dislocation

Figure 9. Schematic cartoon of a subduction zone (redrawn after Hilairet \& reynard, 2009 and Kawano et al, 2011). Two isotherms are represented (1100 and $1400^{\circ} \mathrm{C}$ ). The green region correspond to the serpentinized mantle, the dotted line represent the antigorite breakdown conditions and and the blue arrows represent the putative migration paths of the fluids produced by sediment dehydration. Insert : Magnification of the serpentine channel 
above the subducting slab. Fluids can migrate mostly paralelly to the foliation, promoting the formation of the serpentinized layer above the subducting slab. They can also migrate upwards and hydrate the mantle wedge and contribute to arc magmatism through intracrystalline microcracks.

\section{REFERENCES}

Agard, P., Yamato, P., Jolivet, L., Burov E., 2009. Exhumation of oceanic blueschists and eclogites in subduction zones: Timing and mechanisms. Earth Sci. Rev. 92, 53-79. DOI: 10.1016/j.earscirev.2008.11.002.

Amiguet, E., Van de Moortele, B., Cordier, P., Hilairet, N., Reynard, B., 2014. Deformation mechanisms and rheology of serpentines in experiments and in nature. J. Geophys. Res. 4640-4654.

Andreani, M., Mevel, C., Boullier, A-M., Escartin, J., 2007. Dynamic control on serpentine crystallization in veins: Constraints on hydration processes in oceanic peridotites. Geoch. Geophys. Geosyst. 8, Q02012. DOI: 10.1029/2006GC001373.

Angiboust, S., Langdon, R., Agard, P., Waters, D., Chopin, C., 2011. Eclogitization of the Monviso ophiolite and implications on subduction dynamics. J. Metam. Geol. 30, 37-61. Auzende, A.L., Guillot, S., Devouard, B., Baronnet, A., 2006. Behaviour of serpentinites in convergent context : Microstructural evidence. Eur. J. Mineral. 18, 21-33.

Auzende, A-L., Daniel, I., Reynard, B., Lemaire, C., Guyot, F., 2004. High-pressure behaviour of serpentine minerals: a Raman spectroscopic study. Phys. Chem. Mineral. 31, 269-277. DOI 10.1007/s00269-004-0384-0.

Auzende, A-L., Devouard, B., Guillot, S., Daniel, I., Baronnet, A., Lardeaux, J-M., 2002. Serpentinites from Central Cuba: petrology and HRTEM study. Eur. J. Mineral. 14, 905914.

Bezacier, L., Reynard, B., Bass, J., Sanchez Valle, C., van de Moortele, B., 2010. Elasticity of antigorite, seismic detection of serpentinites, and anisotropy in subduction zones. Earth Planet. Sci. Lett. 289, 198-208.

Chernak, L.J., Hirth, G., 2010. Deformation of antigorite serpentinite at high temperature and pressure. Earth Planet. Sci. Lett. 296, 23-33. 
Chernak, L.J., Hirth, G., 2011. Syndeformational antigorite dehydration producesstable fault slip. Geology 39, 847-850. doi:10.1130/G31919.1.

Christensen, N.I., 2004. Serpentinites, peridotites and seismology. Int. Geol. Rev. 46:795-816.

Deschamps, F., Godard, M., Guillot, S., Hattori, K.H., 2013. Geochemistry of subduction zones serpentinites: A review. Lithos, doi: 10.1016/j.lithos.2013.05.019.

Dobson, D.P., Meredith, P.G., Boon, S.A., 2002. Simulation of subduction zone seismicity by dehydration of serpentine. Science, 298, 407-1410.

Escartin, J., Hirth G., 1997. Non dilatant brittle deformation of serpentinites: Implications for Mohr-Coulomb theory and the strength of faults. J. Geophys. Res. 102, 2897-2913.

Escartin, J., Andreani, M., Hirth, G., Evans, B., 2008. Relationships between the microstructural evolution and the rheology of talc at elevated pressures and temperatures. Earth Planet. Sci. Lett. 268, 463-475. DOI: 10.1016/j.epsl.2008.02.004.

Frey, M., Robinson, D., 1999. Low grade metamorphism. Backwell Sci Ltd pp313.

Fryer, P., Wheat, C.G., Mottl, M.J., 1999. Mariana blueschist mud volcnism: Implications for conditions within the subduction zone. Geology 27, 103-1999. DOI: 10.1130/00917613(1999)027<0103:MBMVIF>2.3.CO;2.

Garth, T., Rietbrock, A., 2014. Order of magnitude increase in subducted H2O due to hydrated normal faults within the Wadati-Benioff zone. Geology 42, 207-210.

Grobety, B., 2003. Polytypes and higher-order structures of antigorite : A TEM study. Am Mineral 88, 27-36.

Guillot, S., Agard, P., Schwartz, S., Vidal, O., 2009. Exhumation processes in oceanic and continental subduction contexts: A review In: Lallemand S, Funiciello F (Eds) Frontiers in Earth Science, 175-205. doi: 10.1007/978-3-540-87974-9_10.

Guillot, S., Hattori, K.H., de Sigoyer, J., Nagler, T., Auzende, A.L., 2001. Evidence of hydration of the mantle wedge and its role in the exhumation of eclogites. Earth Planet. Sci. Lett. 193, 115-127.

Hacker, B.R., Peacock, S.M., Abers, G.A., Holloway, S.D., 2003. Subduction factory - 2. Are intermediate-depth earthquakes in subducting slabs linked to metamorphic dehydration reactions? J. Geophys. Res. 108:B1203. DOI: 10.1029/2001JB001129. 
Hirauchi, K.I., Katayama, I., Uheara, S., Miyahara, M., Takai, Y., 2010. Inhibition of subduction thrust earthquakes by low temperature plastic flow in serpentine. Eart Planet. Sci. Lett. 295, 349-357. DOI: 10.1016/j.epsl.2010.04.007

Hirth, G., Guillot, S., 2013. Rheology and tectonic significance of serpentinite. Elements 9. doi: 10.2113/gselements.9.2.95.

Hermann, J., Müntener, O., Scambelluri, M., 2000. The importance of serpentine mylonites for subduction and exhumation of oceanic crust. Tectonophysics 327, 225-238.

Hilairet. N., Daniel, I., Reynard, B., 2006. Equation of state of antigorite, stability field of serpentines, and seismicity in subduction zones. J. Geophys. Res. 83: L02302. doi:10.1029/2005GL024728.

Hilairet, N., Reynard, B., 2009. Stability and dynamics of serpentinite layer in subduction zone. Tectonophysics 465, 24-29. DOI: 10.1016/j.tecto.2008.10.005.

Hilairet, N., Reynard, B., Wang, Y., Daniel., I, Merkel, S., Nishiyama, N., Petitgirard, S., 2007. High-pressure creep of serpentine, interseismic deformation and initiation of subduction. Science 318, 1910-1913.

Hyndman, R.D., Peacock, S.M., 2003. Serpentinization of the forearc mantle. Earth Planet. Sc. Lett. 212, 417-432.

Jung, H., Karato, S., 2001. Water induced fabric transitions in olivine. Science 293, 14601463.

Jung, H., Green, H.W., Dobrzhinetskaya, F., 2004. Intermediate-depth earthquake faulting by dehydration embrittlement with negative volume change. Nature 428, 545-549

Jung, H., Green, H.W., 2004. Experimental Faulting of Serpentinite duringDehydration: Implications for earthquakes, Seismic Low-Velocity Zones, and Anomalous Hypocenter Distributions in Subduction Zones. Internat. Geol. Rev. 46, 1089-1102.

Jung, H., Fei, Y., Silver, P., Green, H.W., 2009). Frictional sliding in serpentine at very high pressure: Earth Planet. Sci. Lett. 277: 273-279, doi:10.1016/j.epsl.2008.10.019.

Kamiya, S., Kobayashi, Y., 2000. Seismological evidence for the existence of serpentinized mantle wedge. Geophys. Res. Lett. 27, 819-822. 
805

806

807

808

809

810

811

812

813

814

815

816

817

818

819

820

821

822

823

824

825

826

827

828

829

830

831

832

833

834

Katayama, I., Hirauchi, K.I., Michibayashi, K., Ando, J.I., 2009. Trench-parallel anisotropy produced by serpentine deformation in the hydrated mantle wedge. Nature 461, 1114-1117

Kawano, S., Katayama, I., Okazaki, K., 2011. Permeanility anisotropy of serpentinite and fluid pathways in subduction zones. Geology 39, 939-942.

Kunze, G., 1956. Die gewellte struktur des antigorits, I. Zeitsch Kristall 108, 82-107.

Marchesi, C., Garrido, C.J., Padrón-Navarta, J.A., López Sánchez-Vizcaíno, V., GómezPugnaire, M.T., 2013. Element mobility from seafloor serpentinization to high-pressure dehydration of antigorite in subducted serpentinite: Insights from the Cerro del Almirez ultramafic massif (southern Spain). Lithos 15, 128-142.

Mei, S., Kohlstedt, D.L., 2000a. Influence of water on plastic deformation of olivine aggregates. 1. Diffusion creep regime. J. Geophys. Res. 105, 21457-21469

Mei, S., Kohlstedt, D.L., 2000b. Influence of water on plastic deformation of olivine aggregates. 2. Dislocation creep regime. J. Geophys. Res. 105, 21471-21481

Mellini, M., 1982. The crystal structure of lizardite-1T: hydrogen bonds and polytypism. Am. Mineral. 67, 587-598.

Mevel, C., 2003. Serpentinization of abyssal peridotites at mid-ocean ridges. C. R. Geosc. 335, 825-852.

Omori, S., Komobayashi, T., Maruyama, S., 2004. Dehydration and earthquakes in the subducting slab: empirical link in intermediate and deep seismic zones. Phys. Earth Planet. Int. 146, 297-311.

Otten, M.T., 1993. High-resolution transmission electron-microscopy of polysomatism and stacking defects in antigorite. Am. Mineral. 78,75-84.

Padrón-Navarta, J.A., Tommasi, A., Garrido, C.J., Lopez Sanchez, V., 2012. Plastic deformation and development of antigorite crystal preferred orientation in high-pressure serpentinites. Earth Planet. Sci. Lett. 349-350, 75-86.

Padrón-Navarta, J.A., Tommasi, A., Garrido, C.J., Lopez Sanchez, V., Gomez-Pugnaire, M.T., Jabaloy, A., Vauchez, A., 2010. Fluid transfer into the wedge controlled by highpressure hydrofracturing in the cold top-slab mantle. Earth Planet. Sci. Lett. 297, 271-286.

Padrón-Navarta, J.A., López Sánchez-Vizcaíno, V., Garrido, C.J., Gómez-Pugnaire, M.T., Jabaloy, A., Capitani, G., Mellini, M., 2008. Highly ordered antigorite from Cerro del 
Almirez HP-HT serpentinites, SE Spain. Contributions to Mineralo gy and Petrology 156, 679-688

Passchier, C.W., Trouw, R.A., 2005. Microtectonics, Springer, Berlin

Paterson, M.S., Weiss, L.E., 1966. Experimental deformation and folding in phyllite. Geol. Soc. Am. Bull. 77, 343-374. DOI: 10.1130/0016-7606(1966)77[343:EDAFIP]2.0.CO;2

Peacock, S.M., 2001. Are the lower planes of double seismic zones caused by serpentine dehydration in subducting oceanic mantle. Geology, 29, 299-302.

Perrillat, J.P., Daniel, I., Koga, K.T., Reynard, B., Cardon, H., Crichton, W.A., 2005. Kinetics of antigorite dehydration: A real-time diffraction study. Earth Planet. Sci. Lett. 236, 899913. DOI: 10.1016/j.epsl.2005.06.006.

Reynard, B., 2013. Serpentine in active subduction zones. Lithos 178, 171-185.

Scambelluri, M., Muntener, O., Hermann, J., Piccardo, G.B., Trommsdorff, V. (1995) Subduction of water into the mantle: history of an alpine peridotite. Geology 23, 459462.

Schmidt, M.W., Poli, S., 1998. Experimentallu based water budgets for dehydrating slabs and consequence for arc magma generation. Earth Planet. Sci. Lett. 163, 361-379. DOI: 10.1016/S0012-821X(98)00142-3.

Schwartz, S., Lardeaux, J.M., Guillot, S., 2000. The diversity of eclogitic metamorphism in the Monviso ophiolitic complex, western Alps, Italy. Geodyn. Acta. 13, 169-188.

Shea, W.T., Kronenberg, A.K., 1992. Rheology and deformation mechanisms of an isotropic mica schist. J. Geophys. Res. 97, 15201-15237.

Spear, F.S., 1995. Metamorphic Phase Equilibria and Pressure-Temperature-Time Paths. Mineral. Soc. Am., Mon Ser pp799.

Tatsumi, Y., Kogiso, T., 2003. The subduction factory: Its role in the evolution of the earth's crust and mantle. Geol. Soc. London Spec. publ. 2003 219:55-80. doi: 10.1144/GSL.SP.2003.219.01.03.

Ulmer. P., Trommsdorff, V., 1999. Phase relations of hydrous mantle subducting to $300 \mathrm{~km}$, in: Fei Y, Bertka CM, Mysen BO (Eds) Mantle Petrology: Field observations and high pressure experimentations. The Geochemical Society, pp259-281. 
864 Ulmer, P., Trommsdorff, V., 1995. Serpentine stability to mantle depths and subduction865 related magmatism. Science 268, 858-861.

866 van de Moortele, B., Bezacier, L., Trullenque, G., Reynard, B., 2010. Electron back-scattering 867 diffraction (EBSD) measurements of antigorite lattice-prefefred orientations (LPO). J. 868 Microsc. 239, 245-248.

869 van Keken, P., 2003. The structure and dynamics of the mantke wedge. Earth Planet. Sci. $870 \quad$ Lett. 215, 323-338.

871 Viti, C., Hirose, T., 2009. Dehydration reactions and micro/nanostructures in experimentally872 deformed serpentinites. Contrib. Mineral. Petrol. 157, 327-338.

873 von Mises, R., 1928. Mechanics of the ductile form changes of crystals. Zeits. Angewan. 874 Math. Mech. 8, 161-185.

875 Wada, I., Wang, K., He, J., Hyndman, R., 2008. Weakening of the subduction interface and 876 its effects on surface heatflow, slab dehydration, and mantle wedge serpentinization. J. 877 Geophys. Res. 113, B04402. doi:10.1029/2007JB005190.

878 Wang, Y., Durham, W.B., Getting, I.C., Weidner, D.J., 2003. The deformation-DIA: A new 879 apparatus for high temperature triaxial deformation to pressures up to $15 \mathrm{GPa}$. Rev. Sci. $880 \quad$ Instrum. 74, 3002-3011.

881

882

883 


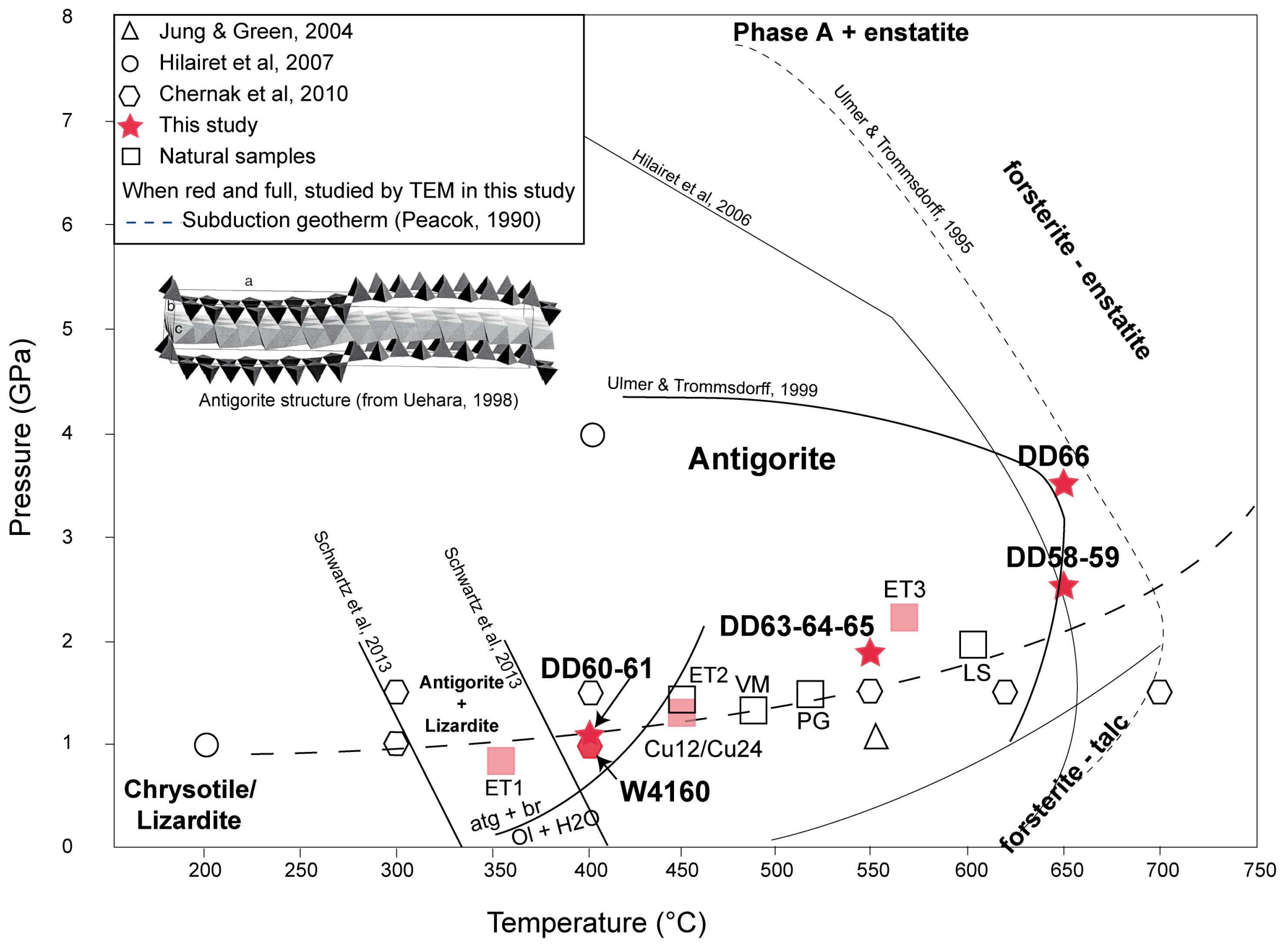




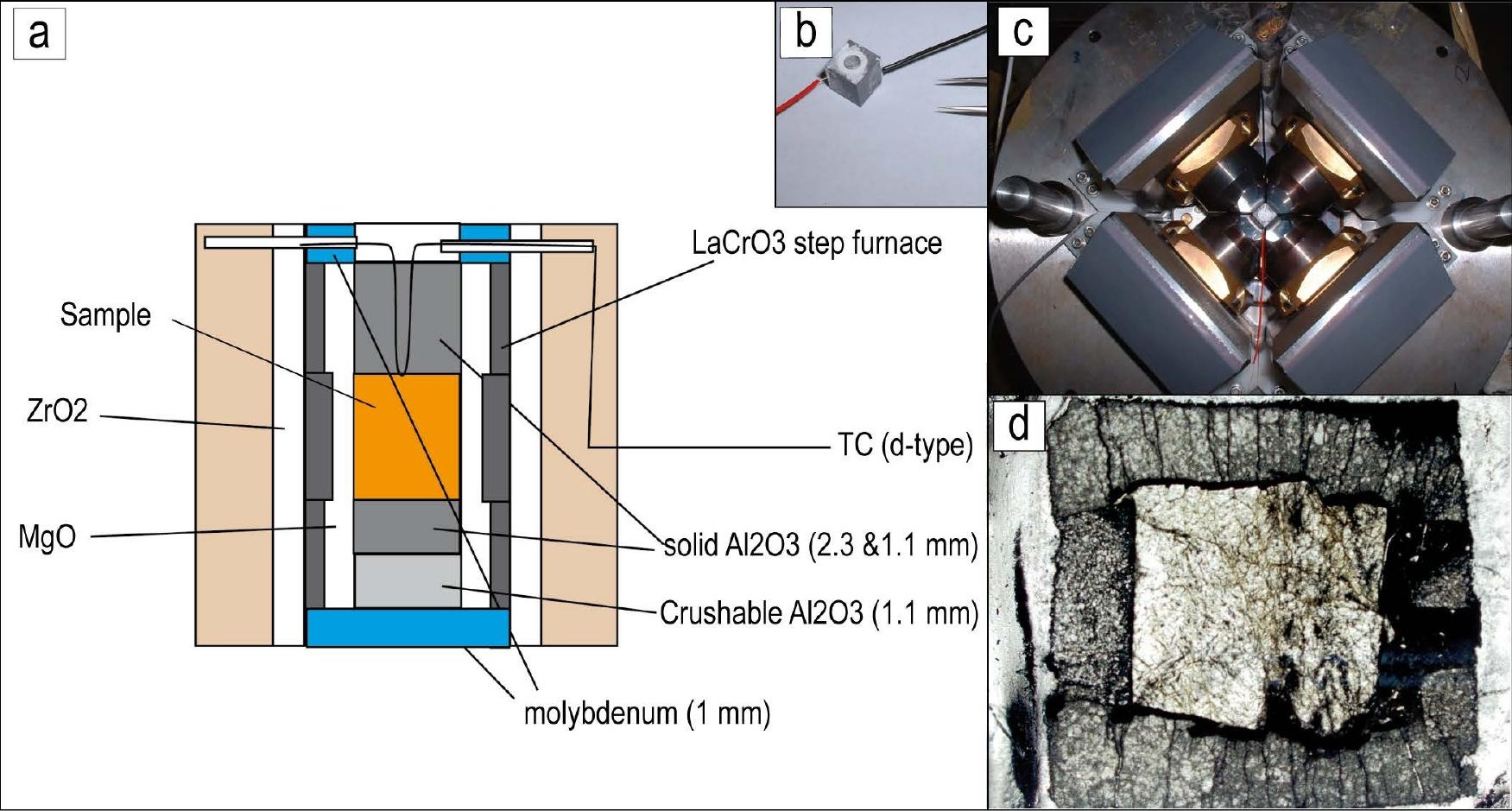




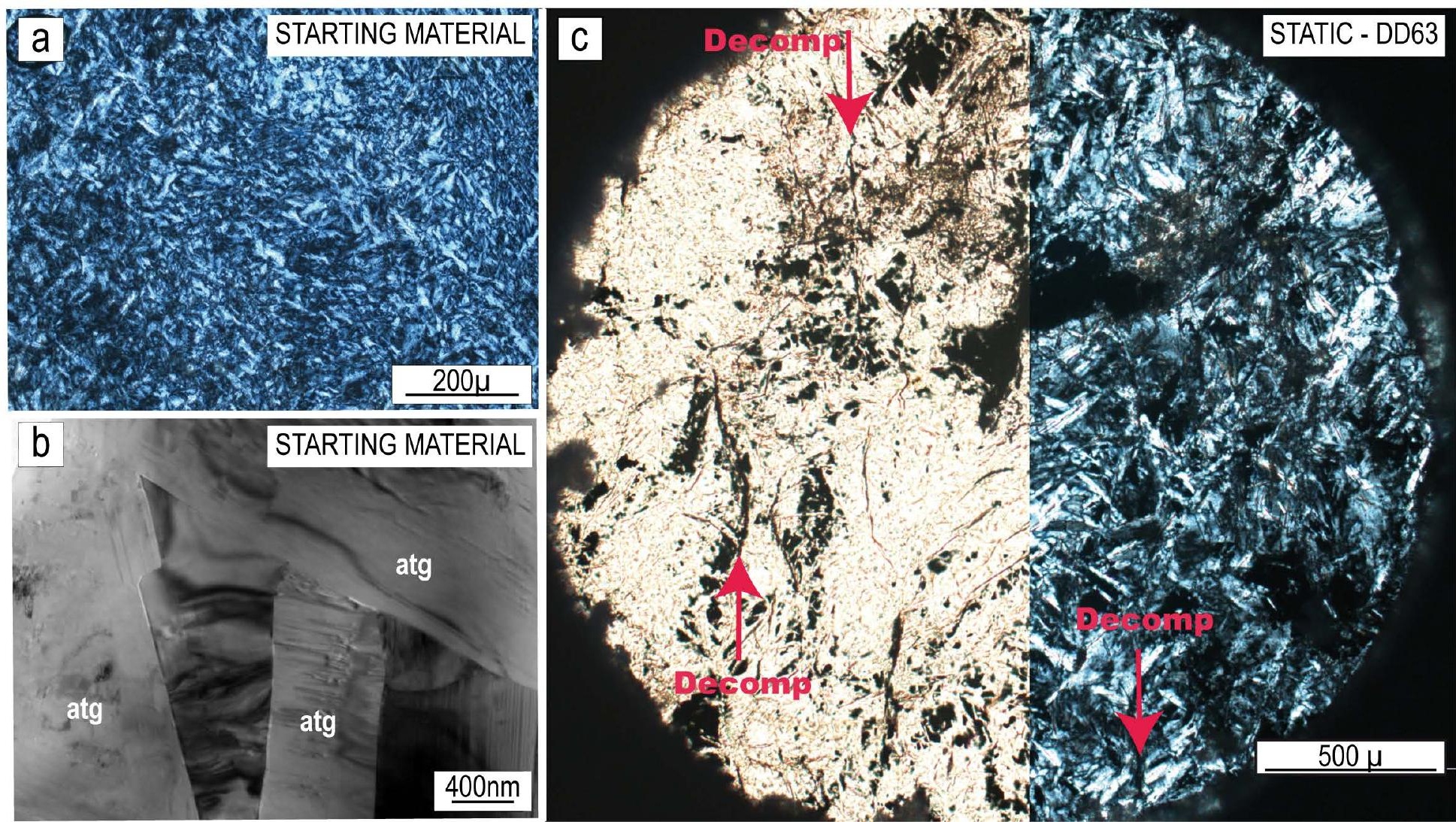




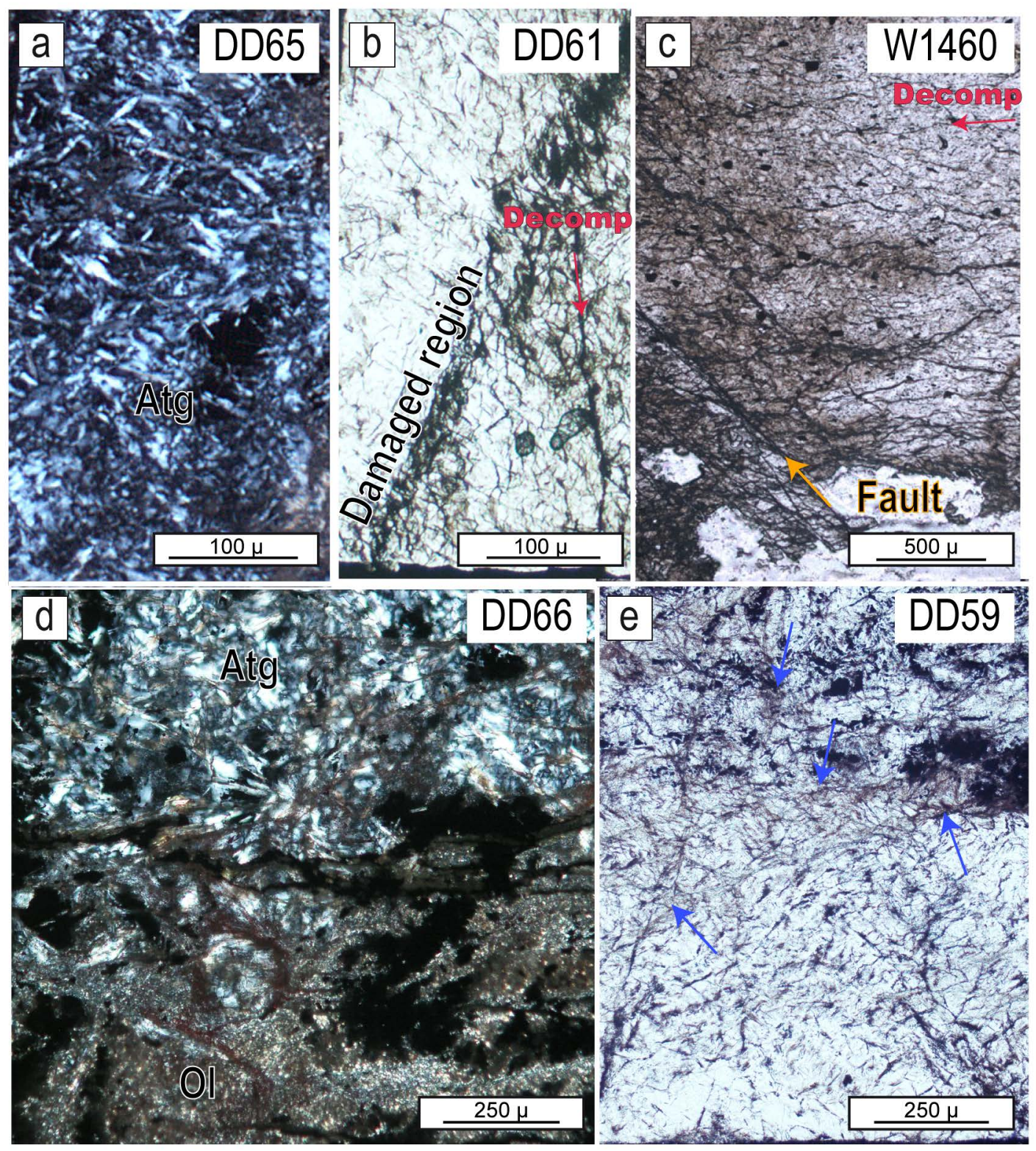




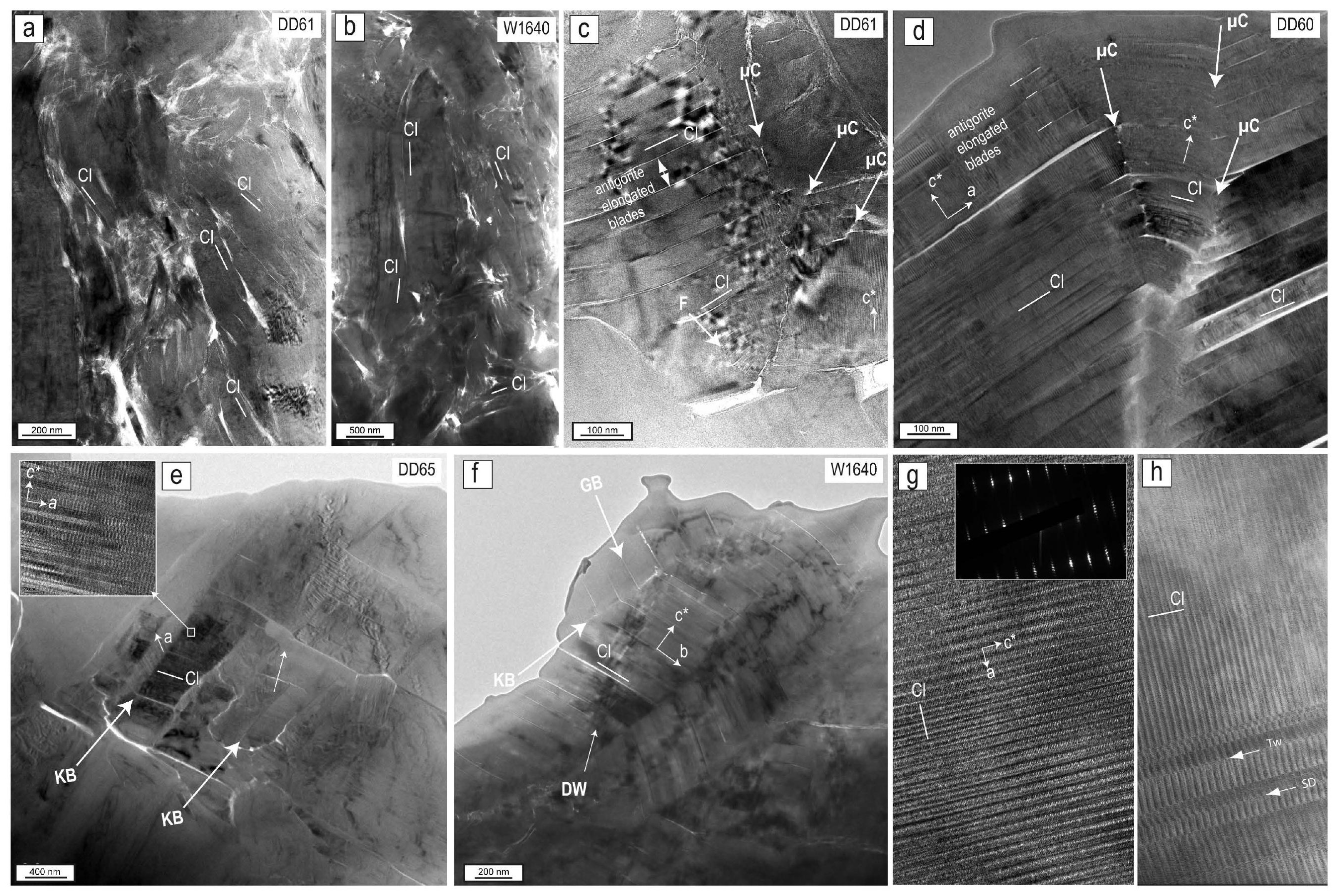




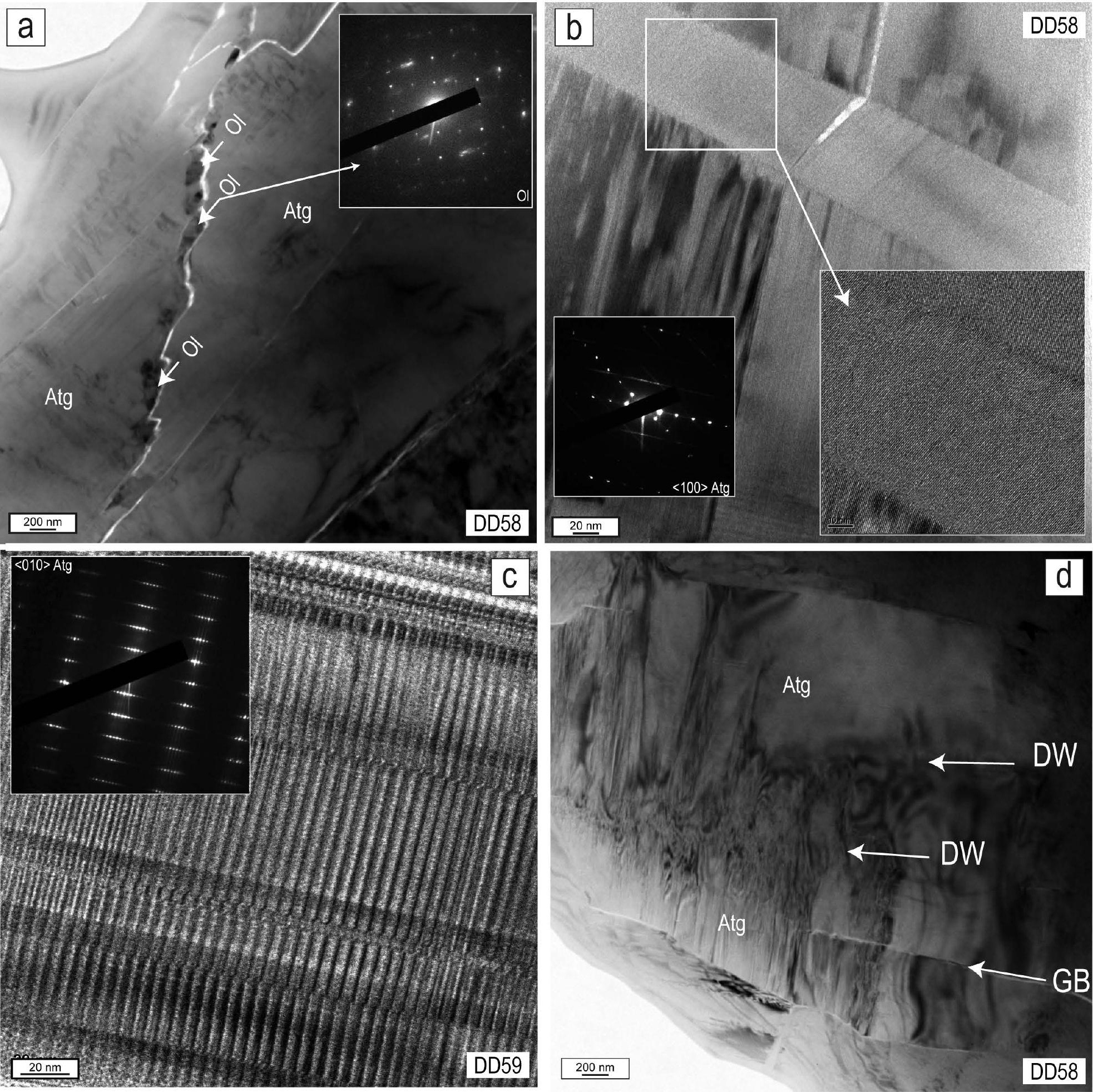




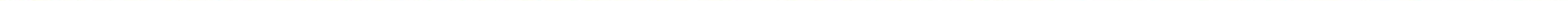




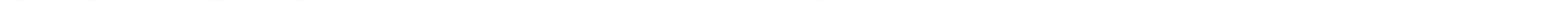


pressure

(kbar)

\section{volcanic arc}

depth
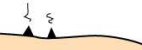

accretion prism

$(\mathrm{km})$

10

20

30

40

50

60

70

microcrack

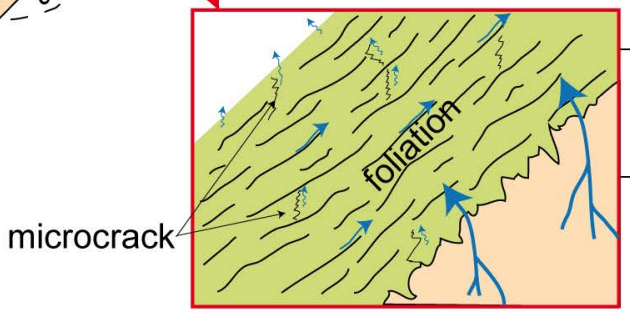

150

200 